\title{
МАКРОЭКОНОМИЧЕСКИЕ ПРОБЛЕМЫ УПРАВЛЕНИЯ: ЕСТЕСТВЕННЫЙ ПРИРОСТ НАСЕЛЕНИЯ
}

\author{
(c) 2020 Зельднер Алексей Григорьевич \\ доктор экономических наук, профессор, главный научный сотрудник \\ Институт экономики РАН, Россия, Москва \\ E-mail: tzeldner@gmail.com
}

Среди показателей, определяющих эффективность макроэкономического управления, важнейший - динамика естественного прироста населения. При всех прочих равных условиях, именно она отражает качество управления социально-экономическим развитием. В статье предпринята попытка рассмотреть системно факторы, которые в наибольшей мере оказывают влияние на естественный прирост населения.

Ключевые слова: управление, демография, естественный прирост, уровень жизни, миграция.

Выступая с посланием Федеральному собранию, Президент страны В. Путин, акцентируя внимание на демографических проблемах, поставил задачу «к середине наступившего десятилетия обеспечить устойчивый естественный рост численности населения страны» [1]. Судя по результатам макроэкономических показателей, у страны имеются возможности для решения поставленных задач. Рост ВВП России в 2019 г. составил 1,3\%, (в 2018 г.-2,5\%). Установлен новый постсоветский рекорд по добыче нефти и газового конденсата - 561 млн. т. Обрабатывающая промышленность в значительной мере за счет пищевой, химической и металлургической отраслей выросла на 2,3\%. Россия завершила 2019 г. с профицитом бюджета 1,6 трлн. руб., Фонд национального благосостояния достиг 6,9\% ВВП (7,7 трлн. руб.), золотовалютные резервы - 540 млрд. долл. При этом долговые обязательства нашей страны - одни из самых низких среди развитых стран. Так что все макроэкономические условия для ускорения роста экономики и повышения уровня жизни населения, как ключевое условие естественного прироста населения, у страны имеются.

В то же время почти все социологические опросы отражают неудовлетворительное материальное положение значительной части населения, к этому следует добавить и рост диффе- ренциации в доходах населения и сложившуюся тенденцию снижения реальных доходов населения (с 2014 г. по 2017 г. почти на 11 процентов, в 2018 г. рост реальных доходов составил 0,1\%). При имеющихся макродостижениях упущено самое главное - социальная сторона развития, социализация роста, и отсюда, как следствие, стагнация реальных доходов, провал в реформировании здравоохранения. Как сухой результат - провал демографической политики, существенное снижение естественного прироста населения.

Складывающаяся на данном этапе тенденция говорит о том, что в стране идет накопление капитала государством и корпорациями * и нарастание денежных проблем у населения. Накопление капитала, по сути, оправдывается ожиданием кризиса, а также тем, что наращивание расходования денежных средств может вызывать рост инфляции. Имеются предложения использовать часть накопленных средств ФНБ на поддержку «государственных экспортных кредитов». Международный валютный фонд рекомендует вкладывать средства в иностранные активы. В общем, вариантов много, но в послании Президента Федеральному собранию прозвучали предложения направить на период до 2024 г. на поддержку малоимущих семей с детьми 1,39 трлн. руб. и на выплаты по программе

\footnotetext{
* «Власти готовятся к мировому кризису, продолжая создавать «заначку» и не афишируя это,- убежден директор Института стратегического анализа ФБК Игорь Николаев. Глобальная экономика замедляется все более явственно. Что же, резон есть, но можно идти по другому пути: не копить, а инвестировать в национальную экономику, чем планомерно занимался Китай. В результате там во время рецессии 2008-2009 гг. темпы роста ВВП лишь снизились с 10\% до 7\%, тогда как другие страны ушли в минус». https:/www.mk.ru/economics/2019/12/15/ dengi-est-pochemu-gosudarstvo-ne-delitsya-sverkhdokhodami-s-naseleniem.html
} 
материнского капитала 1,23 трлн. руб. Проблема, учитывая опыт с реализацией майских указов прошлых лет, в том, чтобы выполнить задуманное. Но это потребует времени, а ситуация с естественным приростом населения уже стоит достаточно остро.

За годы, прошедшие после смены коммунистического режима, численность населения сокращалась вплоть до 2015 г. Стабилизация связана с присоединением Крыма, одновременно снижался и естественный прирост, который частично покрывался за счет миграционного прироста. Но, начиная с 2014 г., миграционный поток начинает сокращаться и уже в 2018 г. он не перекрывает потери от снижения естественного прироста населения.

Если проблемы с естественным приростом населения долгие годы мы объясняли «демографической ямой» (последствия ВОВ и падение рождаемости в 90-е годы), то последнее десятилетие (конкретно пятилетие) можно объяснить скорее экономической ямой и недоработкой правительства в социальной сфере. Череда кризисов и стагнация экономики из-за развала большинства отраслей промышленности, переход за сырьевую модель развития в сочетании с неудачно осуществленной оптимизацией медицины, привело к росту платных услуг. Если к вышеуказанным проблемам прибавить снижение реальных доходов, ежегодный рост цен, тарифов и налогов, то складывается картина, объясняющая устойчивое снижение численности естественного прироста населения.

Сложные, а периодами и трагические мо- менты становления советской власти также не могли не отразиться на демографической ситуации в России: Гражданская война, военный коммунизм, НЭП и борьба с ним, тяжелое становление коллективизации, голодомор, Гулаг, Великая отечественная война, постоянная борьба с врагами народа и другие акции в процессе укрепления диктатуры личности - все это отразилось на сокращении численности населения, естественном приросте и смертности. И советской власти было, что скрывать. Данные численности населения долгие годы находились под грифом «Совершенно секретно». «Согласно постановлению СМ СССР от 1.03.1948 г. № 535-204сс, считалось, что сведения, относящиеся к послевоенной численности населения, считались совершенно секретными и входили в перечень главнейших сведений, составляющих государственную тайну» [2]. Потери численности населения за период 1917-1940 гг. до сих пор точно не подсчитаны, и таких цифр в открытой печати найти не удалось.

Данные о потерях в Великой отечественной войне постепенно стали достоянием общественности. В интервью газете «Правда» от 14.03.1946 г. И.В. Сталин отметил, что СССР «потерял в боях с немцами, а также оккупации и угону советских людей... около семи миллионов человек». В годы ВОВ, по расчетам специалистов комиссии по человеческим потерям в войне 1941-1945 гг., погибло 25,3 млн. граждан страны. Комиссия к этому добавила потери, связанные со смертностью детей, родившихся в годы войны, примерно 1,3 млн. чел., итого общие потери в годы войны составили 26,6 млн. человек [3].

Таблица 1. Некоторые демографические показатели населения РСФСР за 1940-1949 гг.

\begin{tabular}{|c|c|c|c|c|}
\hline \multirow{2}{*}{ Показатели } & \multicolumn{4}{|c|}{ Годы } \\
\hline & $1940 * *$ & 1945 & 1948 & $1949[4]$ \\
\hline \multicolumn{5}{|c|}{ Общая численность (тыс. чел.) } \\
\hline Родившихся & 6118 & 2506 & 4194 & 5042 \\
\hline Умерших & 3535 & 1885 & 1922 & 1755 \\
\hline Естественный прирост & 2583 & 621 & 2272 & 3287 \\
\hline Уд.вес естественного прироста к родившимся, \% * & 42,3 & 24,8 & 54,2 & 65,2 \\
\hline Уд.вес умерших в к родившимся,\% * & 57,7 & 75,2 & 45,8 & 34,8 \\
\hline \multicolumn{5}{|c|}{ На 1000 чел. населения (чел.) } \\
\hline Родившихся & 33,0 & - & - & - \\
\hline Умерших & 20,6 & - & - & - \\
\hline Естественный прирост & 12,4 & - & - & - \\
\hline
\end{tabular}

* Расчет автора

** Данные за 1940 г. из: Народное хозяйство РСФСР за 60 лет. М. Статистика. 1977. С. 19 
Анализ таблицы показывает, что в 1940 г. в РСФСР естественный прирост населения составлял 12,4 на 1000 населения (в 1913 г. этот показатель был 15,4$)$ и за последние десятилетия мы ни разу к нему не приблизились. Следует отметить, что в 1940 г. число родившихся составляло 33 чел. на тысячу населения, но была очень высокая смертность (20,6 чел. на тысячу населения). Естественный прирост населения отмечался и с 1950 по 1965 годы.

Официальная трактовка снижения численности населения в России объясняется демографическими «ямами», и такая версия имеет право на существование. Как правило, большинство аналитиков первую демографическую яму, связывают с Великой отечественной войной, и в этом плане следует отметить, что уже в 1960 г. статистикой зафиксирован высокий естественный прирост населения (15,9 человека на 1000 населения), спустя пять лет в 1965 г. [5] естественный прирост составил 8,1 человека на 1000 населения, а смертность соответственно 7,4 и 7,6. Суммарный коэффициент рождаемости в конце 50-х годов прошлого века составлял 2,6, в 1958-1959 г.- 2,63 ребенка на одну женщину [6]. Эти показатели остались недосягаемы до сих пор. Такой всплеск рождаемости можно объяснить только высоким духовным подъемом людей, переживших войну и голодные годы. Война, естественно, отразилась на общей численности населения, но победа породила надежды на лучшую жизнь, отсюда и естественный прирост населения. Коэффициент рождаемости в 19611962 гг.-2,417, и выше двух он продержался до 1985-1986 гг.-2,111. В 1990 г. коэффициент составил 1,887 [7].

За период с 1950 г. по 1960 г. сохранялся положительный естественный прирост населения, как в целом по СССР [8], так и по РСФСР, в основном за счет снижения численности умерших на 1000 человек населения. За десятилетие с 1960 по 1970 г. естественный прирост населения проявлял положительный тренд за счет тех же тенденций, что и в прошлом десятилетии. Восьмидесятые годы прошлого века были в социально-экономическом плане достаточно успешными, хорошими показателями завершалось выполнение продовольственной программы, рос уровень жизни, и население отреагировало естественным приростом. С 1979 по 1989 г. население РСФСР выросло на 10 млн. человек. Все эти годы естественный прирост населения был положительным, а коэффициент рождаемости в середине десятилетия в 1985-1986 гг. составлял 2,111.

Шоковые реформы девяностых годов оказали существенное влияние на уровень жизни населения, на сельское хозяйство и промышленность и сразу же последовала реакция населения. С 1992 г. отмечается отрицательный естественный прирост, и так до 2010 г. и далее. Небольшой положительный тренд отмечен в 2014 и 2015 гг. $(0,2-0,3)$, а далее опять снижение естественного прироста населения нарастающими темпами. Это следствие, в первую очередь, экономической политики правительства. Резкий переход на сырьевую модель развития, стагнация несырьевой экономики, формирование олигархического капитализма, приведшего к существенной дифференциации населения по доходам. С 1992 г. начал снижаться в России естественный прирост населения. Если еще в 1990 г. естественный прирост населения составлял 332 тыс. человек, то уже в 1995 г. было минус 893 тыс.человек. В целом численность населения России за 19902000 гг. сократилась на 2 млн. человек. Эта тенденция сохраняется и на текущее десятилетие, что показано в таблице 2.

Судя по данным таблицы, снижение численности населения продолжается с 2000 г. по 2014, с 2015 г. рост населения связан с включением в общую статистику населения Крыма (свыше 2 млн. чел.). В целом снижается естественный прирост населения. Одновременно меняется баланс миграции. Низкий уровень реальных доходов приводит к оттоку мигрантов. За последние три года число прибывших в Россию снизилось на 10 тыс. чел., а выбывших - выросло на 127 тыс. чел. Естественный прирост населения уже с 2018 г. не перекрывается количеством мигрантов, приезжающих в Россию. Это достаточно тревожная тенденция, учитывая еще такой фактор, как снижение суммарного коэффициента рождаемости.

В целом следует отметить, что складывающаяся в России демографическая ситуация это уже не демографическая яма, а рукотворная экономическая яма. Проведенный нами анализ показывает, что нарастание негативных экономических процессов в значительной мере и предопределило сложившуюся демографическую ситуацию в стране (таблица 3).

В целом в стране с 1990 г. идет снижение численности населения с небольшими перепадами. Так крымское население в 2015 г. обеспечило 
Таблица 2. Естественное движение населения России (2000-2018 гг.)

\begin{tabular}{|c|c|c|c|c|c|c|c|}
\hline \multirow[b]{2}{*}{ Годы } & \multicolumn{3}{|c|}{ На 1000 чел.населения } & \multirow{2}{*}{$\begin{array}{c}\text { Числен- } \\
\text { ность насе- } \\
\text { ления, млн. } \\
\text { чел. }\end{array}$} & \multirow{2}{*}{$\begin{array}{c}\text { Прибыло в } \\
\text { Россию, тыс. } \\
\text { чел. }\end{array}$} & \multirow{2}{*}{$\begin{array}{c}\text { Выбыло из } \\
\text { России, тыс. } \\
\text { чел. }\end{array}$} & \multirow{2}{*}{$\begin{array}{l}\text { Суммарный } \\
\text { коэфф. рож- } \\
\text { даемости на } \\
1 \text { женщину }\end{array}$} \\
\hline & родившихся & умерших & $\begin{array}{l}\text { естеств. } \\
\text { прирост }\end{array}$ & & & & \\
\hline 2000 & 8,7 & 15,3 & $-6,6$ & $145,6 *$ & 359,3 & 145,7 & 1,19 \\
\hline 2005 & 10,2 & 16,1 & $-5,9$ & 143,2 & 177,2 & 69,8 & 1,29 \\
\hline 2010 & 12,5 & 14,2 & $-1,7$ & 142,9 & 191,6 & 33,5 & 1,56 \\
\hline 2014 & 13,3 & 13,1 & 0,2 & 143,7 & 590,8 & 310,5 & 1,75 \\
\hline 2015 & 13,3 & 13,0 & 0,3 & $146,3 * *$ & 598,6 & 353,2 & 1,77 \\
\hline 2016 & 12,9 & 12,9 & - & 146,5 & 575,2 & 313,2 & 1,76 \\
\hline 2017 & 11,5 & 12,4 & $-0,9$ & 146,8 & 589,0 & 377,1 & 1,62 \\
\hline 2018 & 10,9 & 12,5 & $-1,6$ & 146,9 & 565,7 & 440,8 & $1,5 * * *$ \\
\hline
\end{tabular}

* Данные по численности населения за 2000 г. из: Российский статежегодник. Госкомстат. М. 2001. С. 82

** Рост общей численности населения России с 2015 г. объясняется тем, что с этого года учитывается и население Крыма.

*** Это показатель за 2019 г. По предварительной оценке коэффициент рождаемости составит 1,5. По мнению В. Путина, в 2024 г. коэффициент рождаемости должен быть 1,7 (Российская газета. 16.01.2020. С. 2)

**** Данные за 2005, 2014, 2018 гг. из: Россия в цифрах 2019. С. 33, 77, 79, 81. Остальные данные из: Российский статистический ежегодник 2018. Росстат. М. 2018. С. 96.

добавочно более 2 млн. человек. Также перепадами характеризуется миграционный прирост, который с 2017 г. резко снижается и уже не покрывает убыль естественного прироста населения. Отрицательный показатель естественного прироста с 2000 г. снизился только к 2015 г., но падение реальных доходов с 2014 г. и рост численности населения с доходами ниже прожиточного минимума оказали существенное влияние на показатели естественного прироста населения. Расслоение населения по доходам и их существенная дифференциация также отразились на естественном приросте населения.

Коэффициент фондов (коэффициент дифференциации доходов), отражающий уровень социального расслоения населения и рассчитывающийся, как отношение среднего уровня доходов 10\% населения с самыми высокими доходами к 10\% населения с самыми низкими доходами с 1990 г. вырос в 3,5 раза с 4,4 (1990 г.) до 15,5 (2018 г.). А коэффициент Джини, характеризующий уровень распределения доходов населения от 0 до 1 (чем выше значение коэффициента, тем более неравномерно распределяются доходы), увеличился за послереформенный период в 1,4 раза. Если к этому добавить неудачный эксперимент по оптимизации здравоохранения, то взаимосвязь демографических и социальноэкономических факторов на данном этапе развития России чрезвычайно тесная, что и отражается на естественном приросте населения. Экономические факторы создают проблемы и с миграцией. Ситуация, сложившаяся в России с естественным приростом населения характерна для развивающихся стран с низким и средним уровнем жизни и таким же здравоохранением. Следует отметить, что проблема снижения коэффициента рождаемости характерна и для многих развитых стран, но там проблема решается на качественно другой базе, регулирующей доступность населения к современному здравоохранению.

Анализ показывает, что наблюдаемый почти 20 лет отрицательный естественный прирост населения,- следствие трех важнейших факторов:

1. Шоковое реформирование общественной системы; 2. Непродуманная оптимизация в течение последнего десятилетия здравоохранения; 3. Снижение уровня жизни населения, которому просто не хватает средств на платную медицину, набирающую обороты в стране и на содержание детей из-за систематического роста цен, тарифов и налогов и стагнирования реальной заработной платы.

Не последнюю роль в росте тенденции снижения численности населения страны сыграла реформа здравоохранения, начатая якобы с благородными намерениями по оптимизации бюджетных расходов в здравоохранении за счет закрытия неэффективных больниц и медучреждений, фактически привела к разрушению ее первичного звена. По оценке экспертов Центра экономических и политических реформ (ЦЭПР), в результате оптимизации с 2000 г. по 2015 г. в 

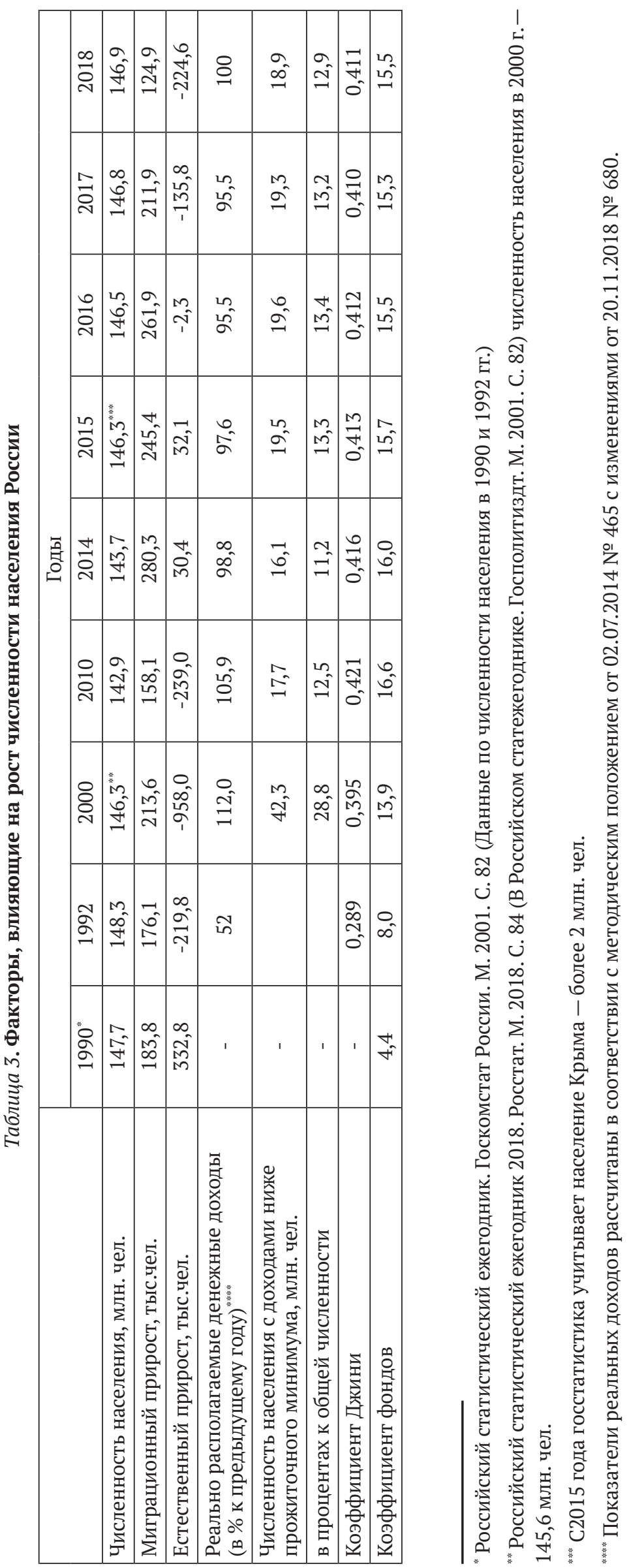
России в два раза сократилось число больниц с 10,7 тыс. до 5,4 тыс. Количество поликлиник уменьшилось на 12,7\% - до 18,6 тыс. По оценке вице-премьера Татьяны Голиковой, «оптимизация была проведена ужасно во многих российских регионах и качество и доступность услуг в ее результате резко ухудшились». Т. Голикова отметила, что в таком выполнении оптимизации «виноваты все - и центр, и регионы». Сейчас необходимо исправлять сложившуюся ситуацию» [9].

По мнению директора Института демографии ВШэ А. Вишневского, «у нас плохо работает система здравоохранения, ответственная за главный фактор высокой смертности, то есть за сердечно-сосудистые заболевания. На Западе давно уже говорят о «кардиоваскулярной революции», вероятность умереть от этой причины существенно снизилась, у нас этого пока не произошло. Низкая эффективность нашей системы здравоохранения обусловлена ее направленностью, прежде всего, на лечение болезней, а охрана здоровья в наше время - это еще и эффективная профилактика, влияющая на весь образ жизни людей... Одним словом, со здравоохранением у нас явно что-то не так» [10].

«По прогнозу ООН (2019 г.) в Европе к середине XXI века останется только две страны с уровнем естественного прироста выше уровня воспроизводства, 215 детей на 100 женщин. Это Швеция и Норвегия, но в Швеции на здравоохранение тратится 12,5\% ВВП» [11]. А в России в 2018 г. на здравоохранение из консолидированного бюджета было израсходовано 3315 млрд. руб., это 3,2\% ВВП страны". В последних майских указах Президента была поставлена задача обеспечения «устойчивого естественного роста численности населения страны», снижения уровня бедности в 2 раза и достижения темпов экономического роста выше среднемирового, и все это к 2024 г. Надежда на нацпроект «Демография».

В опубликованном Росстатом демографическом прогнозе до 2035 г. «согласно пессимистичному варианту за 16 лет численность населения сократится со 146 млн. в 2020 г. до 134,2 млн., по среднему - до 142,9 млн., согласно оптимистичному - вырастет до 150 млн. В 2020 году по худшему прогнозу при естественной убыли в 484,4 тыс. человек в страну приедут 190,8 тыс. человек.
Средний вариант предполагает убыль в 355,7 тыс. и миграционный прирост в 265 тыс., оптимистичный - убыль в 239,3 тыс. и миграционный прирост в 339,8 тыс. Во всех вариантах прогноза естественный прирост населения является отрицательным, в низком и среднем вариантах миграция компенсирует его частично и общая численность населения падает» [12]. Проблема более чем серьезная, учитывая размеры России, ее роль в обеспечении природными ресурсами,рост населения России в первую очередь за счет естественного прироста необходимо признать важнейшим фактором национальной безопасности.

В конце декабря 2019 г. Росстат сообщил, что зафиксировано ускорение естественной убыли населения страны, предварительно более чем на 300 тыс. человек. Миграционный прирост не обеспечивает компенсацию естественной убыли. Более того, в стране снижается численность женщин в репродуктивном возрасте [13].

Падение естественного прироста населения - это не только демографическая, а проблема национальной безопасности страны. Падение показателя рождаемости означает старение населения, сокращение численности работающих, возникновение проблем нехватки высококвалифицированных работников, а это фактор роста производительности труда. Возникают и другие не менее сложные проблемы - снижение численности населения автоматически ведет к снижению численности потребителей, а, следовательно, падает спрос. Падение спроса (при прочих равных условиях) приводит к падению предложения, а это уже проблема расширенного воспроизводства. В будущем - это проблема выживания нации. Отсюда для страны, стремящейся сохранить лидирующие позиции в мире, возникает ряд проблем, обозначим некоторые:

Первая - необходимо отработать систему приоритетов, обеспечивающих комфортный уровень жизни населения, включающую, в первую очередь, рост реальной заработной платы, обеспечивающей, как минимум, трехкратный МРОТ на каждого члена семьи, далее, вернуться к системе обеспечения семей с детьми бесплатным социальным жильем и гарантией на бесплатное обеспечение яслями, садами, школьным питанием и обучением в средних и высших учебных заведениях. Кроме того, для семей с

" Россия в цифрах 2019. Росстат. М. 2019. С. 33, 423. Удельный вес расходов на здравоохранение в ВВП составил: в 2015 г. $-3,4 \%$, в 2016 г. $-3,6 \%$, в 2017 г. $-3,1 \%$. 
детьми ввести льготные тарифы на все услуги ЖКХ, включая квартплату. И все это в сочетании с бесплатным для детей и взрослых здравоохранением.

Вторая - следует расширить подготовку специалистов среднетехнического звена, четко скоординированную с современными технологическими процессами, с отраслевыми министерствами, с корпорациями и ведущими объединениями. Нехватка специалистов современной формации - недоработка системы управления.

И третья проблема, требующая четко продуманной программы, особенно учитывая, что почти все страны мира сталкиваются с нехваткой квалифицированных специалистов и работников, необходимо грамотно подойти к проблеме иммиграции. Если вспомнить историю России, особенно до 1917 г., то стоит отметить, что страна всегда прибегала к привлечению квалифицированных иностранных кадров, создавая для них условия.

\section{Библиографический список}

1. Российская газета. 16.01.2020.

2. http://istmat.info/node/39967

3. https://tass.ru/info/6036200

4. www.demoscope.ru/weekly/2015/0655/arxiv04.php

5. Народное хозяйство РСФСР за 60 лет. М. Статистика. 1979 г. С. 19.

6. Российский статистический ежегодник 2018. С. 97.

7. Российский статистический ежегодник. Госстат России. М. 1995. С. 71

8. Народное хозяйство СССР в 1960 г. Статежегодник. М. 1961. С. 60

9. https://www.rbc.ru/rbcfreenews/5e02d8b19a79473c2779152c

10. https://www.znak.com/2020-01-08/rossiya_vymiraet_ili_optimiziruetsya_pochemu_ubyl_naseleniya_stala_ neobratimoy (Вишневский А.)

11. https://www.mk.ru/economics/2019/12/15/dengi-est-pochemu-gosudarstvo-ne-delitsya-sverkhdokhodami-snaseleniem.html

12. https://www.svoboda.org/a/30203079.html

13. https://www.rbc.ru/society/27/12/2019/5e053fb69a7947adc5872160

14. Зубаревич Н. Тенденции развития российских регионов. (https:/www.znak.com/2019-12-16/economist_ natalya_zubarevich_rasskazala_sovfedu_o_tom_chto_meshaet_strane_razvivatsya)

15. Российский статистический ежегодник. Госкомстат России. М. 2001.

16. Россия в цифрах 2019. Краткий статистический сборник. Росстат. М. 2019 